\title{
SENTIDOS E SIGNIFICADOS DA DOCÊNCIA NA EJA
}

\author{
Mirna Vieira Martinez ${ }^{1}$ Veronice Camargo da Silva ${ }^{2}$
}

\begin{abstract}
${ }^{1}$ Universidade Estadual do Rio Grande do Sul. Rua Sete de Setembro, 1156, Centro, CEP: 90010-191, Porto Alegre, RS, Brasil. Fone: (51) 3288.9070 E-mail: mirna-martinez@uergs.edu.br

2 Universidade Estadual do Rio Grande do Sul, Av. Tupy Silveira, 2820- B. São Jorge. CEP 96408-700, Bagé, RS. e-mail: veronicesilva@uergs.edu.br
\end{abstract}

Resumo-Este artigo é um recorte feito numa pesquisa denominada: Sentidos e significados da docência: formação, processos pedagógicos, gestão e políticas educacionais da EJA". Foi aplicado um questionário com perguntas abertas e fechadas, aplicado a 97 professores que atuam na EJA em escolas estaduais, onde os dados foram recolhidos no Seminário de Formação Continuada no município de Bagé. Os referenciais teóricos utilizados foram: Freire (1998), Arroyo (2011), Scheibel (2010), Sant'Anna (2001; 2014) entre outros. Foram selecionadas para análise as perguntas referentes ao aspecto da identidade docente. No qual, é descrito quem são os professores da EJA, como eles se constituíram e como se definem na sua prática docente. Para a análise foi utilizada a metodologia de análise de conteúdo acrescidas das observações da autora do texto na sua experiência como palestrante em diversos encontros de formação nas diversas regiões de abrangência das CRES (Coordenadorias Regionais de Educação) do Rio Grande do Sul. Os resultados parciais apontam para a necessidade de formação constante e continuada em seminários que proporcionem práticas reflexivas onde cada um possa se reconhecer como sujeito e que os auxilie na sua prática docente coerente com as características da EJA.

Palavras-chave - Identidade Docente. Seminários de Formação. Professores da EJA.

Abstract - This article is an excerpt made in a denominated search: Senses and meanings of teaching: training, pedagogical processes, management and educational policy of the EJA ". It applied a questionnaire with open and closed questions, applied to 97 teachers who work in adult education in public schools; data were collected in seminars of Continuing Education in the town of Bage. The theoretical references were: Freire (1998), Arroyo (2011), Scheibel (2010), Sant'Anna (2001; 2014), among others. The questions regarding the aspect of teacher identity were selected to be analyzed. It is described who the teachers of EJA are, how they were formed and how they define themselves in their practice of teaching. For the analysis, we used the content analysis methodology plus the text of the author's observations on his experience of working in several training meetings in many different regions spanning the CRES (Coordinate Regional Education) of Rio Grande do Sul state. The partial results point to the constant and continuing education need in seminars that provide reflective practices where each one can be recognized as a subject and that can be assisted in their teaching practice consistent with the characteristics of adult education.

Keywords - Teacher Identity. Training Seminars. Adult Education Teachers.

Recebido em: 25 de novembro de 2015 Aprovado em: 31 de dezembro de 2015

\section{INTRODUÇÃOO}

O presente artigo é um recorte da pesquisa "Sentidos e significados da docência: formação, processos pedagógicos, gestão e políticas educacionais da EJA" em que uma das autoras atuou como participante do grupo de pesquisa, além de ser mediadora nas formações promovidas pela SEDUC, UERGS e UFRGS nas diversas regiões de abrangências das CREs em todo o Rio Grande do Sul. Os dados foram coletados a partir de um questionário com perguntas fechadas e abertas, aplicado a professores/as que atuavam na EJA em escolas estaduais. Para este artigo foram analisadas questões referentes à identidade dos docentes da EJA no município de Bagé. Inicialmente, foram questionados há quanto tempo atuavam como professores e o tempo de atuação na EJA. Também em que nível de ensino eles atuavam. Ainda, foram consultados se as formações continuadas atendiam as suas necessidades tendo que justificar a sua resposta de forma subjetiva e quais as principais necessidades enfrentadas na prática pedagógica.

Foram obtidas 97 respostas ao instrumento de pesquisas. Selecionaram-se as questões que se referem à identidade docente, mais especificamente como o professor se percebe no seu agir docente e na sua formação.

Também, acrescentam-se nessa análise as impressões da pesquisadora que atuou como formadora nos seminários de formação continuada neste projeto e, ainda, ao longo da caminhada na EJA como formadora há mais de dez anos, inicialmente, no município de Sant'ana do Livramento e após, no município de Bagé.

Nessa trajetória docente, constatou-se que o professor que atua na EJA possui um diferencial na prática docente, quer no conjunto de saberes construídos nos estudos, quer nas formações propiciadas pela gestão do Sistema Educacional, no planejamento cooperativo e coletivo, nas experiências vividas junto aos alunos da 
EJA, quer na prática diferenciada que necessita ser reinventada diariamente.

É tarefa do professor da EJA compreender o aluno e a realidade de onde o mesmo vem, seus anseios, dificuldades, necessidades e singularidades e, acima de tudo, acolhê-lo e acreditar na possibilidade de que ele pode vencer as barreiras e desafios do cotidiano.

Ainda, cabe ao professor analisar as diferenças e semelhanças dos seus alunos, já que hoje as nossas salas de aula da EJA apresentam um perfil diferente, pois muitos jovens estão frequentando a escola nessa modalidade o que faz com que os interesses dos alunos jovens sejam diferentes dos alunos adultos.

Com isso, o professor (a) da EJA, no dizer de Arroyo (2001) necessita de uma realização profissional e humana mais plena. $\mathrm{Na}$ visão do autor:

\begin{abstract}
Seremos obrigados a ver as crianças, os adolescentes e os jovens e adultos com que se convive nas salas de aula como humanos plenos, em processo de formação na totalidade de potencialidades humana e em formas de viver tão precarizadas, assumir essa complexa tarefa como um trabalho profissional terminará por alargar o projeto de realização profissional e humana a que todo docente tem direito como ser humano pleno que é. (p.26)
\end{abstract}

Ainda, reforça o autor, que aprender com os educandos a sermos educadores amplia e enriquece nosso projeto de realização profissional e humana, pois "nestes tempos somos obrigados a mudar nossas práticas e nosso trabalho, somos levados a repensar-nos em nossas identidades profissionais" (ARROYO, 2011, p.27).

A grande maioria dos docentes participantes da formação, atua na EJA num tempo de 1 a 10 anos (56 professores) e, há mais de 10 anos que atua na EJA, totalizam 10 professores. Os outros respondentes atuam na EJA, mas, na função de orientadoras, supervisoras e diretoras. Salienta-se que 9 professores não responderam aos questionamentos.

As escolas em que os docentes atuam atendem os níveis: 23 os Anos Finais; 22 Anos Finais e Médio; 22 atendem Anos Iniciais e Finais; 3 atendem todos os níveis. Quatro professores não responderam e 20 indicaram o atendimento somente no Nível Médio.

\section{METODOLOGIA}

A metodologia utilizada na investigação partiu dos pressupostos da pesquisa qualitativa em educação. Isso não significa, porém, que os dados quantitativos deixaram de se fazer presentes nesse cenário. $\mathrm{O}$ que se salienta, assim, é que prevalecem na análise geral sobre as informações coletadas, a qualidade das mesmas e essas são passíveis das interpretações sobre as realidades apresentadas.

Conforme Minayo (2007), a pesquisa qualitativa deve ter como principal preocupação, a lógica que permeia a prática que se dá na realidade, correspondendo a um processo mais profundo de relações, processos e fenômenos que não podem ser reduzidos a variáveis, já que a pesquisa qualitativa se constitui na coparticipação entre os sujeitos envolvidos no processo, que corroboram de sentidos, significados e representações sociais, que permeiam os espaços investigados.

Nessa perspectiva, a metodologia, juntamente com análise dos dados, constitui-se na especificação e explicitação de um corpus teórico que permita a constituição de um campo de conhecimento capaz de reler e ressignificar a própria EJA.

O olhar sobre os dados foi feito mediante o enfoque da Análise de Conteúdo. Segundo Bardin (1977) na Análise de Conteúdo o texto é um meio de expressão do sujeito, em que o analista busca categorizar as unidades de texto (palavras ou frases) que se repetem ou se articulam, inferindo uma expressão que as representem. Nesta perspectiva, Bardin (1977, p.9) afirma que o investigador precisará primar também em sua análise:

[...] pelo escondido, o latente, o não-aparente, o potencial de inédito (do não dito), retido por qualquer mensagem. Tarefa paciente de «desocultação», responde a esta atitude de voyeur de que o analista não ousa confessar-se e justifica a sua preocupação, honesta, de rigor científico.

Esta forma de interpretação, mediante estratégias específicas de organização dos conteúdos textuais possibilitam um olhar aprofundado sob os aspectos de interesse da pesquisa.

\section{DISCUSSÃO}

\subsection{Os professores (a) da EJA - Identidade docente}

Ao serem perguntados como se compreendem e se identificam como educadores da EJA, muitas manifestações referem-se a: "necessidade de crescimento pessoal constante"; " a interação com os colegas nos diferencia"," sentimos que muitas vezes fazemos a diferença na vida de muitos alunos".

Paulo Freire (1996, p. 48) indica que o educador que age com autonomia deve, acima de tudo, pensar certo, o que envolve uma ação dialógica e comprometida. Para ele:

[...] A tarefa coerente do educador que pensa certo é, exercendo como ser humano a irrecusável prática de inteligir, desafiar o educando com quem se comunica e a quem comunica, produzir sua compreensão do que vem sendo comunicado. Não há inteligibilidade que não seja comunicação e intercomunicação e que não se funde na dialogicidade. $\mathrm{O}$ pensar certo por isso é dialógico e não polêmico

A autonomia diz respeito à escola e aos professores. Os professores devem estar em permanente processo de atualização e ação - reflexão sobre sua prática pedagógica, para que possam promover estratégias diferenciadas e aulas mais interessantes, fazendo com que os alunos, atualmente mais espertos e preparados, voltem para a aula com vontade de aprender e conhecer. Os conteúdos devem estar vinculados à realidade dos mesmos, suprindo seus interesses e necessidades.

Tendências consideradas teóricas, hoje incentivam a formar professores abertos às inovações e que saibam 
utilizar as ferramentas tecnológicas para promover uma aprendizagem real, significativa e produtiva, voltada não para a preparação de alunos que apenas aprenderam os conteúdos, mas para a formação de cidadãos que aprenderam, que participaram do processo de ensino/aprendizagem, e que, principalmente, sejam construtores do seu próprio conhecimento, mediados pela intervenção de um professor mediador- inovador.

A escola voltada para o diálogo possibilita que seus professores desenvolvam um processo dialógico também em sala de aula, cujos alunos serão beneficiados, pois conforme Padilha (2001, p.23):

Esse diálogo introduz educadores e educandos num novo sentido educativo, em que a fala é permitida, é requerida e em que todos aprendem a ouvir, a escutar o outro (...). Passa a existir um clima democrático no qual todos têm voz, todos podem lutar por seus direitos (...), com a certeza de que suas palavras serão ouvidas, discutidas e serão objetos da reflexão de seus companheiros. Aqui, o aluno passa a ter um papel que lhe foi historicamente negado pela educação bancária.

Em oposição a esse tipo de educação, surge uma pedagogia voltada para o diálogo, para uma relação horizontal entre professor e aluno, em que existe confiança e comunicação entre eles. Segundo Romão (2003, p.20), Freire, há muito tempo, falava da importância dessa pedagogia para transformação da educação, ou seja, "o diálogo é um instrumento fundamental na teoria e prática freirianas".

Esse tipo de educação possui como uma das características fundamentais o diálogo, que começa na busca dos conteúdos, pois os mesmos são significativos, contextualizados com a realidade dos alunos. Conteúdos esses que procuram ser trabalhados dentro das necessidades dos educandos, pois de acordo com Freire, (1987, p.102):

Enquanto na prática "bancária" da educação, antidialógica por essência, por isto, não- comunicativa, o educador deposita no educando o conteúdo programático da educação, que ele mesmo elabora ou elaboram para ele, na prática problematizadora, dialógica por excelência, este conteúdo que jamais é " depositado ", se organiza e se constitui na visão de mundo dos educandos (...).

Para alcançar essa rápida evolução, surge a necessidade de uma educação voltada para a formação de cidadãos mais capacitados para enfrentar a dura realidade que os cerca.

Começa a surgir uma nova teoria preocupada com a formação de um sujeito mais crítico, mais humano, solidário e, principalmente, construtor do seu conhecimento. O aluno passa a ocupar lugar central no processo, mas mediado pelo professor.

De acordo com Vasconcellos, (2002, p.89)
Esta postura de construção do conhecimento implica uma mudança de paradigma pedagógico, qual seja, ao invés de dar o raciocínio pronto, de fazer para/pelo aluno, o professor passa a ser o mediador da relação educando objeto de conhecimento - realidade, ajudandoo a construir a reflexão, pela organização de atividades, pela interação e pela problematização; os conceitos não devem ser dados prontos; podem ser construídos pelos alunos, propiciando que caminhem para a autonomia.

A sala de aula que possui uma dinâmica voltada para a dialogicidade propicia aos seus alunos um aprendizado diferenciado porque possibilita que os mesmos participem em todo o processo, proporcionando, assim, a construção de saberes de forma estratégica resultando na formação de alunos, já desde então dialógicos.

Ao conceituar e explicar a noção de Identidade pode-se concordar com Woodward (2000, p.10) que "a construção da identidade é tanto simbólica quanto social". Ela ressalta a importância da construção de um quadro teórico que possa dar uma compreensão mais ampla dos processos que estão envolvidos na construção da identidade.

Para ela, a construção da identidade é relacional, e a diferença é estabelecida por uma marcação simbólica relativamente a outras identidades. Também, a identidade caracteriza-se pela sua vinculação a condições sociais e materiais.

Nessa relação o social e o simbólico referem-se a dois processos diferentes, mas cada um deles é necessário para a construção e a manutenção das identidades. Ainda, Woodward (2000, p.17) adiciona outro elemento que é a representação, assim expressa:

\begin{abstract}
A representação inclui as práticas de significação e os sistemas simbólicos por meio dos quais os significados são produzidos, posicionando-nos como sujeito. É por meio dos significados produzidos pelas representações que damos sentido à nossa experiência e àquilo que somos. Podemos inclusive sugerir que esses sistemas simbólicos tornam possível aquilo que somos e aquilo no qual podemos nos tornar.
\end{abstract}

$\mathrm{Na}$ construção da identidade do profissional da educação, a questão pessoal é extremamente importante, já que a figura do professor como pessoa e profissional são referências inseparáveis, pois é uma profissão construída sobre fundamentos ético-filosóficos e impregnada de valores e de intencionalidade, que configuram um projeto existencial que explica a dimensão humana da docência.

A inseparabilidade da pessoa e do profissional é justificada por Nóvoa (1997, p.31) quando diz que "ser professor obriga a opções constantes que cruzam nossa maneira de ensinar, e que desvendam na nossa maneira de ensinar a nossa maneira de ser".

A identidade do professor define-se num equilíbrio entre as características pessoais e profissionais, do que se conclui que suas ações traduzem a plenitude de sua 
pessoa, da mesma forma que a compreensão da humanidade do docente ajuda a compreender a prática profissional.

\subsection{Identidade e profissionalização}

A partir das manifestações que destacam como a formação influencia a sua profissão, os professores apontam que: "a motivação para a melhoria do trabalho em sala de aula"; " a busca por fundamentação teórica que permita auxiliar como trabalhar com os alunos diferenciados possibilitando acréscimo para a prática docente". São expressões que revelam a necessidade crescente de maior profissionalização.

Segundo Tardif (2003, p.11), "na realidade, no âmbito dos ofícios e profissões, não creio que se possa falar do saber sem relacioná-lo com os condicionantes e com o contexto do trabalho". Acrescenta ainda que esse saber é sempre "o saber de alguém que trabalha alguma coisa no intuito de realizar um objetivo qualquer".

Ao esclarecer de maneira mais aprofundada esse saber indica que "não é algo que flutua no espaço: o saber dos professores é o saber "deles" e está relacionado com a pessoa e a identidade deles, com a sua experiência de vida e com a sua história profissional, com as suas relações com os alunos em sala de aula e com os outros atores na escola".

O professor é um profissional cuja atividade principal é o ensino. A formação visa propiciar os conhecimentos, as habilidades e atitudes requeridas para levar adiante o processo de ensino e, na atualidade, a ênfase na aprendizagem dos alunos nas escolas. Esse conjunto de requisitos profissionais que tornam alguém um professor, muitos autores denominam de profissionalidade. Para Libâneo (2001, p.63), "a conquista da profissionalidade supõe a profissionalização e o profissionalismo".

Ao conceituar a profissionalização pode-se relacioná-la às condições ideais que venham a garantir o exercício profissional de qualidade que envolve a formação inicial e a formação continuada, em que o professor aprende a desenvolver as competências, habilidades e atitudes profissionais.

Já o profissionalismo implica um desempenho competente e compromissado dos deveres e responsabilidades que constituem a especificidade de ser professor e, também, o comportamento ético e político expresso nas suas atitudes relacionadas à prática profissional.

Na prática, pode-se perceber isso como o domínio que ele tem da matéria que leciona, a aplicação competente de estratégias e métodos de ensino, a sua dedicação ao trabalho, assim como sua participação consciente na construção coletiva da proposta pedagógica da sua escola, que deve ser democrática.

Em última instância, essas ideias auxiliam na construção e no fortalecimento da identidade profissional do professor.

Acredita-se que a profissionalidade dos educadores está em processo de construção, ela implica muito mais que um título, cujo sentido é relativo num sistema cada vez mais credencialista. Tudo isso é perpassado por melhores condições de trabalho, remuneração e prestí- gio social. Implica lutar por um maior controle autônomo do próprio trabalho num marco ético, centralizado nos homens e nas mulheres e no seu bem-estar e dignidade. Portanto, é necessário enfrentar o desafio de construção de um sentido de profissionalidade que dê aos educadores o reconhecimento social pela sua tarefa.

\subsection{A prática docente na EJA}

Muitos professores manifestaram que as formações continuadas são essenciais para a sua profissionalização, mas, que muitas vezes, elas não atendem as suas reais necessidades e indicam que: "gostaria que fossem mais específicas para a área que atuo"; "com mais atividades práticas"; "somos motivados nas formações mas ao chegar na escola não há condições e nem se contemplam as nossas expectativas".

Ainda, expressaram que enfrentam muitas dificuldades no trabalho para propor aos alunos da EJA que são desmotivados, com inúmeras dificuldades de aprendizagem, com diferenças muito grande na idade e nas expectativas, baixa autoestima conflitos geracionais, indisciplina, muitas vezes, ocasionada pelo consumo de drogas, altas taxas de infrequência o que ocasiona que haja necessidade de estar sempre começando e revisando os conteúdos, assim como, a falta de recursos como laboratórios (informática, química) para o desenvolvimento de aulas diferentes.

Ao analisar as questões referentes sobre professor e professor reflexivo, Pimenta (2002) aponta que a reflexão é característica fundamental de todo ser humano. Ela é atributo característico dos seres humanos. Portanto, a autora questiona se todo ser humano reflete por que essa moda de professor reflexivo.

No início dos anos 90 do século XX, essa expressão tomou conta do cenário educacional, confundindo a reflexão enquanto adjetivo, como atributo próprio do ser humano, com um movimento teórico de compreensão do trabalho docente.

Para diferenciá-los, foram feitos estudos sobre a gênese contextualizada desse movimento. Schön (2000) realizou atividades relacionadas com reformas curriculares nos cursos de formação de profissionais. Observou as práticas e, valendo-se dos seus estudos sobre John Dewey, propôs que a formação não fosse nos moldes de um currículo normativo que primeiro apresenta a ciência, depois sua aplicação e por último um estágio que supunha a aplicação pelos alunos dos conhecimentos técnico-profissionais

Nessa visão, a valorização da experiência e a reflexão na experiência além do conhecimento tácito apontam para que Schön (2000) aposte numa formação profissional baseada numa epistemologia da prática, ou seja, na valorização da prática profissional como momento de construção de conhecimento, através da reflexão, análise e problematização dela, e o reconhecimento tácito, presente nas soluções que os profissionais encontram em ato.

Complementando, pode-se dizer que esse conhecimento na ação é o conhecimento tácito, implícito, interiorizado, que está na ação e que, portanto, não a pre- 
cede. Ele é mobilizado pelos profissionais no seu dia- a -dia, configurando um hábito. Mas só isso não é suficiente. Diante de novas situações, os profissionais criam, constroem novas soluções, novos caminhos o que se dá por um processo de reflexão na ação. A partir daí, constroem um repertório de experiências que mobilizam em situações similares, configurando um conhecimento prático. Mas estes por sua vez não dão conta de novas situações que colocam problemas que superam o repertório criado, exigindo uma busca, uma análise, uma contextualização, um diálogo com outras perspectivas "uma apropriação de teorias sobre o problema, uma investigação, enfim" (p.20). A esse movimento o autor denomina reflexão sobre a reflexão na ação. Isso conduz à ideia de um professor pesquisador.

Pimenta (2004, p.21), considera que Schön manifesta: "uma forte valorização da prática na formação dos profissionais, mas uma prática refletida, que lhes possibilite responder às situações novas, nas situações de incerteza e indefinição".

Essas ideias foram rapidamente apropriadas e ampliadas em diferentes países, num contexto de reforma curricular, em que os profissionais precisam ensinar em situações singulares.

Por isso se tornou muito forte a ideia de formação contínua na escola, na explicitação das demandas da prática. Essa formação contínua não pode ser entendida como treinamento ou simples capacitação e vai além do conceito de educação permanente. Os eixos que daí decorrem são o da valorização da pesquisa e da prática na formação de professores.

As primeiras críticas que surgiram foram quanto ao "practicismo", que segundo Zeichner (1997), emergem. Este autor aponta que Schön não especifica as reflexões sobre a linguagem, os sistemas de valores, os processos de compreensão e a forma com que define o conhecimento, e que sem eles não se consegue mudar a produção do ensino, de forma igualitária e justa. Acrescenta que só a reflexão não basta, o professor necessita tomar posições concretas para reduzir tais problemas.

Diante da necessidade de alargar a ideia, Contreras (1997) apud Pimenta (2002) chama a atenção "para o fato de que a prática dos professores precisa ser analisada, considerando que a sociedade é plural, no sentido da pluralidade de saberes, mas também desigual, no sentido das desigualdades sociais, econômicas, culturais e políticas" (p. 25).

Decorre dessa contextualização a necessidade de movimentar-se da reflexão individual à coletiva e finalmente para a reflexão crítica. Para que isso ocorra, há que se enfatizar o papel da teoria.

No prólogo da obra, Kemmis aponta que Carr (1996) o ajudou a ver que, muitas vezes, a ancoragem em velhas posturas apesar da sensação de progresso é evidente e desafia os educadores a repensar o papel da investigação educativa como suporte para orientar a prática e os professores.

Acrescenta que "temos que interessarmo-nos tanto pelas teorias dos "práticos" como estamos pelas suas práticas e, precisamos estudar as práticas dos "teóricos" de maneira tão minuciosa como o fazemos com suas teorias, demonstrando, também, que o trabalho da prática educativa e o da elaboração teórica devem desenvolver-se de forma conjunta" (p. 19).

\section{CONCLUSÃO}

É notório, a partir da presente análise, que a prática docente alimentada pelo seu contínuo questionamento tende a aperfeiçoar-se e a encontrar caminhos diferentes, particulares. É sabido, também, que o questionamento sistemático só acontece na vida profissional do docente quando este ultrapassa a fase inicial do "ensaio e erro", na qual sua maior preocupação é descobrir / experimentar estratégias e procedimentos didáticos que lhe permitam atuar com um certo grau de segurança.

Portanto, o processo de formação profissional inclui uma progressiva descoberta dos atos de trabalho que o professor realiza diuturnamente e sobre os quais ele racionaliza. Esse processo de descoberta e autoconstrução tem papel decisivo na construção da identidade do professor.

Os dados apontam que o processo de construção da identidade dos professores está constantemente se reconstruindo, é algo inacabado. Ela é tanto individual quanto social.

Após a análise das questões iniciais do instrumento foi possível perceber como os seminários de formação desenvolvidos nas diversas regiões e, principalmente, em Bagé relatado neste artigo, são momentos de reflexão que os professores participantes desencadeiam a partir das temáticas abordadas, como professor da EJA, metodologias e avaliações na EJA e a prática docente. Onde os saberes desencadeados podem ser um elo motivador para o desenvolvimento de novas experiências nas salas de aula.

No início de cada seminário de formação foram apresentadas "Boas práticas" desenvolvidas por escolas da rede estadual e isso estimula outros docentes a criarem novas experiências práticas.

Nas falas e depoimentos dos professores expressadas em diversos momentos refletem o que constitui a sua vida pessoal e profissional e como eles se relacionam com seus alunos, a vibração quando atingem o sucesso na aprendizagem deles. Também abordam as dificuldades em fazê-los interagir e se motivar para participar de projetos transformadores para a sua vida e, aqueles que conseguem, traduzem a sua satisfação.

\section{REFERÊNCIAS}

ARROYO, Miguel. Currículo, território em disputa. Petrópolis: Vozes, 2011.

\section{BARDIN, Laurence. Análise de Conteúdo. Lisboa: Edições 70, 1977.}

FREIRE, Paulo. Pedagogia do Oprimido. Rio de Janeiro: Paz e Terra,1987.

FREIRE, Paulo. Pedagogia da autonomia. São Paulo: Paz e Terra, 1997. 
NAVARRO, P.; DIAZ, C. Análisis de contenido. In: DELGADO, J.M.;GUTIERREZ, J. Métodos y técnicas cualitativas de investigación en ciencias sociales. Madrid: Síntesis, 1994.

LIBÂNEO, José Carlos. Organização e gestão da escola. São Paulo: Alternativa, 2006.

PADILHA, Paulo Roberto. Planejamento Dialógico: como construir o projeto político-pedagógico da escola. São Paulo: Cortez; Instituto Paulo Freire, 2001.

PIMENTA, Selma Garrido (Org). O professor reflexivo no Brasil: gênese e crítica de um conceito. São Paulo: Cortez, 2002.

PIMENTA, Selma; ANASTASIOU, Lea. Docência no Ensino Superior. São Paulo: Cortez, 2002.

ROCHA, Raquel. Práticas de Alfabetização na Educação de Jovens e Adultos. São Paulo: Cortez,2013.

ROMÃO, José Eustáquio. Pedagogia Dialógica. São Paulo: Cortez, 2002.

SANT'ANNA, Sita Mara Lópes. Aprendendo com Jovens e Adultos. Porto Alegre: UFRGS,2001.

SANT'ANNA, Sita Mara Lópes. Olhares Múltiplos e Contemporâneos da Educação de Jovens e Adultos. Porto Alegre: Uergs,2014.
SCHÖN, Donald. La formación de profesionales reflexivos: hacia un nuevo diseño de la enseñanza y el aprendizaje en las profesiones. Barcelona: Paidós, 1992.

SCHÖN, Donald. Formar professores como profissionais reflexivos. In: NÓVOA, Antonio. Os professores e a sua formação. Lisboa: Publicações Dom Quixote, 1992.p.77-91.

SILVA, Tomaz Tadeu da (Org.). Identidade e diferença: a perspectiva dos Estudos Culturais. Petrópolis: Vozes, 2000.

TARDIF, Maurice. Saberes profissionais dos professores e conhecimentos universitários: elementos para uma epistemologia da prática profissional dos professores e suas consequências em relação à formação para o magistério. Revista Brasileira de Educação, Rio de Janeiro, n. 13 jan./fev./mar./abr. 2000, p.5-24.

TARDIF, Maurice. Saberes docentes e formação profissional. Petrópolis: Vozes, 2003.

VASCONCELLOS, Maria José Esteves. Pensamento Sistêmico: o novo paradigma da ciência. Campinas: Papirus, 2002.

WOODWARD, Kathryn. Identidade e diferença: uma introdução teórica e conceitual. IN: SILVA, Tomaz Tadeu da. Identidade e diferença: a perspectiva dos estudos culturais. Petrópolis: Vozes, 2000. 